\title{
Importance of Midwifery Care in the Prevention of Postpartum Depression
}

K. Janouskova (Kristina Janouskova)

Department of Nursing and Midwifery, Faculty of Health Care Studies,

University of West Bohemia, CZ.

\section{E-mail address:}

kjanousk@kos.zcu.cz

\section{Reprint address:}

Kristina Janouskova

Department of Nursing and Midwifery

Faculty of Health Care Studies

University of West Bohemia

Husova 11

30100 Plzen

Czech Republic

Source: Clinical Social Work and Health Intervention

Pages: $98-106$

Volume: 12

Issue: 4

\section{Reviewers:}

Gabriela Lezcano

University of California, San Francisco, USA

Roberto Cauda

Institute of Infectious Diseases, Catholic University of the Sacred Heart, Rome, IT

\section{Keywords:}

Midwife. Puerperium. Postpartum Depression. Breastfeeding. Newborn care.

\section{Publisher:}

International Society of Applied Preventive Medicine i-gap

CSWHI 2021; 12(4): 98 - 106; DOI: 10.22359/cswhi_12_4_12 @ Clinical Social Work and Health Intervention

\section{Abstract:}

Introduction. This article focuses on the importance of midwife care for women in the puerperium period for the prevention of postpartum depression. This care is mostly preventive; therefore, education occupies an important place. Using appropriate education and preventive strategies, many complications or problems, such as postpartum depression, can be minimized or recognized in time.

Methodology: The research method was a controlled nursing experiment. The essence was to compare two different groups and find to what extent the care of a midwife contributes to the prevention of postpartum depression. The experimental group consisted of 100 women with the care of a midwife in the puerperium period, where three visits took place during the puer- 
perium period, throughout which the Edinburgh Postpartum Depression Scale EPDS was used to assess mental health. The control group consisted of 100 women without the care of a midwife in the puerperium period. A questionnaire was sent to these women at the end of the sixth week, along with an EPDS scale.

Results: A statistically significant correlation was found between the risk of postpartum depression and problems with neonatal care $(\mathrm{p}=0.016)$. There was also a statistically significant difference in the incidence of problems with newborn care according to the presence of a midwife $(\mathrm{p}=0.005)$ and midwifery care in the area of breastfeeding $(\mathrm{p}=0.049)$. The distribution of the results of the EPDS scale did not differ statistically significantly $(\mathrm{p}=0.775)$ depending on the care of a midwife.

Conclusion: The results showed that the care of a midwife leads to the prevention of health complications in women in the puerperium period. The care of a midwife does not lead to the identification of postpartum depression more often, but symptoms are recognized earlier, and treatment is started. A midwife's care can also reduce the predisposition to postpartum depression. Women attended to by a midwife showed fewer problems with breastfeeding or newborn care, which are two of the predictors of postpartum depression risks.

\section{Introduction}

A midwife is a non-medical health professional who provides primary care during pregnancy, childbirth and the puerperium period for physiological women and newborn babies. A midwife plays a significant role during the postpartum period, when a woman comes home with a new member of her family after giving birth. A midwife is able to provide both health services and, especially in the postpartum period, important psychological support. Through their care and presence, a midwife contributes to reducing maternal and neonatal morbidity and mortality (1). Most women in the Czech Republic, mostly primiparas, come home from the maternity hospital after 72 hours and cannot imagine taking care of themselves and a newborn baby. The most common problems that occur in the puerperium period are problems with breastfeeding or care of the newborn baby. The woman's psyche is also exposed to great strain. Firstly, due to hormonal and physical changes, but also due to adaptation to the new role of the mother. Mood swings during the puerperium period are common. However, if mood deterioration is pro- longed and is accompanied by anxiety, fear, helplessness, or loss of interest and pleasure, it can result in postpartum depression (2).

Postpartum depression is a worldwide problem. Globally, up to 150 women per 1,000 live births suffer from depression (3). The worldwide incidence of postpartum depression is around 10$15 \%$. However, it is clear that the prevalence of postpartum depression can range from 0 to $60 \%$ depending on various influencing factors (4). A systematic review of 291 studies from 56 countries indicated an even higher prevalence of postpartum depression of $17.7 \%$ (5). However, the incidence of postpartum depression can also be affected by the frequency of its testing.

Postpartum depression affects a woman's life, her whole family, but also the child's development. In some cases, depression can grow into postpartum psychosis. In the Czech Republic, postpartum depression is not adequately addressed. This is a problem about which pregnant women and women in the puerperium period often have no information. There are no large numbers of self-help groups or organizations in the Czech Republic. The highest numbers of 
women suffering from postpartum depression meet in discussion forums where they go for advice concerning their children. According to research, the prevention of postpartum depression includes intensive and professional postpartum care (6) provided by a midwife during the puerperium period.

Community care provided by a midwife is not a service commonly utilized in the Czech Republic, although its benefits are well-known. The care provided by a midwife is still seen as above standard, for which women have to pay extra money in most cases, because cooperation with insurance companies and district gynecologists is not integrated enough. Women who do not have their own midwife seek help during the puerperium period from by district gynecologists, who often treat their problems with medication, although in some cases a thorough education and a change in the family's daily routine would suffice.

\section{Methods}

Goal: Find to what extent the care of a midwife who uses preventive strategies in their work can influence the onset of postpartum depression.

Research cohort:

The research group consisted of 200 women in the puerperium period, who were deliberately selected. 100 women with the care of a midwife in the puerperium period in the experimental group and 100 women in the control group without the care of a midwife. The deliberate selection eliminated a serious medical history in a woman's history, including blood loss of more than 1,500 $\mathrm{ml}$, TEN, pulmonary embolism, uterine rupture and perineal rupture of $3 \mathrm{~b}$ grade during the delivery, which could distort the research results.

Methodology:

The method of research was a controlled nursing experiment. The essence was the comparison of the results within the experimental group of women and the control group of women. The experimental group included selected women in the puerperium period who were visited at least 3 times by a midwife during the puerperium period in a community setting. The women were informed about the goals of the research and signed an informed consent document. Standards of care were established to en- sure the uniformity of care provided by each midwife. Each midwife also had documentation available. The control group included selected post-puerperium women who did not receive community care by a midwife. A questionnaire was sent to these women to their e-mail addresses which they had made available at the maternity hospital. The questionnaire focused on their: obstetric history; their newborn; the course of breastfeeding; physical and mental changes after childbirth; adaptation to the role of the mother; support from the environment.

The Edinburgh Postpartum Depression Scale (EPDS) was used to screen postpartum depression in all respondents. The EPDS was always distributed during the last visit by the midwife at the end of the puerperium period or sent to the email addresses of the women in the control group. The scale has ten questions, including a question regarding suicidal thoughts. Scoring takes place on a scale from zero to three. In women who score higher than 12 and have never experienced postpartum depression, there is $86 \%$ sensitivity and $78 \%$ specificity for postpartum depression. Women must fill in the EPDS completely by themselves; EPDS is quickly evaluated by trained staff. With a score higher than 13 points, it is likely that a woman suffers from postpartum depression of varying severity. However, an assessment of the client's overall condition and clinical examination is also required to confirm the diagnosis. This scale assesses how a woman has felt over the past week. If recurrence is required, it is advisable to repeat the examination after two weeks (7). The total score is calculated by adding the circled numbers for all ten items together. The higher the score, the more likely it is that the person who completed this questionnaire is or may be depressed. It is only a monitoring tool that should not be used to directly diagnose depression.

Data processing:

Descriptive statistics (frequency tables with absolute and relative numbers) were used to describe the data. A chi-square test was used to test the monitored parameters. Statistical tests were evaluated at a significance level of 5\%. Processing was performed by the program Stata v. 10. 


\section{Results}

The experimental group with the care of a midwife consisted of 100 women, mainly firsttime mothers $(69 \%)$, with a university degree (54\%). The control group then consisted of 100 women without the care of a midwife during the puerperium period, mostly multiparas $(60 \%)$ with secondary education $(60 \%)$. The respondents were mostly women after vaginal delivery in both the experimental $(68 \%)$ and control groups $(77 \%)$. From the health point of view, women in the puerperium period; suffered prima- rily from suture pain $(37 \%)$; painful or bleeding hemorrhoids $(16 \%)$ or an increased risk of postpartum depression (24\%) in both study groups (Table 1). The group of women who had community care provided by midwives in their puerperium period included three women who had to seek medical help. The group where the women did not have community care provided by a midwife included eleven women who had to seek medical help, and three who needed a telephone consultation with a doctor.

Table 1 Basic data

\begin{tabular}{|c|c|c|c|c|c|c|}
\hline & \multicolumn{2}{|c|}{$\begin{array}{l}\text { Community care } \\
\text { provided by a } \\
\text { midwife } n=100\end{array}$} & \multicolumn{2}{|c|}{$\begin{array}{l}\text { No community care } \\
\text { provided by a } \\
\text { midwife } n=100\end{array}$} & \multicolumn{2}{|l|}{$\begin{array}{l}\text { Total } \\
\mathbf{n}=\mathbf{2 0 0}\end{array}$} \\
\hline \multicolumn{7}{|l|}{ Demographic data } \\
\hline & $\begin{array}{l}\text { Absolute } \\
\text { number }\end{array}$ & $\%$ & $\begin{array}{l}\text { Absolute } \\
\text { number }\end{array}$ & $\%$ & $\begin{array}{l}\text { Absolute } \\
\text { number }\end{array}$ & $\%$ \\
\hline Primiparas & 69 & $69 \%$ & 40 & $40 \%$ & 109 & $55 \%$ \\
\hline Multiparas & 31 & $31 \%$ & 60 & $60 \%$ & 91 & $45 \%$ \\
\hline University education & 54 & $54 \%$ & 15 & $15 \%$ & 69 & $35 \%$ \\
\hline Secondary education & 38 & $38 \%$ & 60 & $60 \%$ & 98 & $49 \%$ \\
\hline Elementary education & 8 & $8 \%$ & 25 & $25 \%$ & 33 & $16 \%$ \\
\hline \multicolumn{7}{|l|}{ Method of delivery } \\
\hline Vaginal delivery & 68 & $68 \%$ & 77 & $77 \%$ & 145 & $73 \%$ \\
\hline $\begin{array}{l}\text { Operational delivery } \\
\text { (VEX, Forceps) }\end{array}$ & 5 & $5 \%$ & 2 & $2 \%$ & 7 & $3 \%$ \\
\hline Caesarean & 27 & $27 \%$ & 21 & $21 \%$ & 48 & $24 \%$ \\
\hline \multicolumn{7}{|c|}{ Health problems during the puerperium period } \\
\hline Urinary incontinence & 1 & $1 \%$ & 6 & $6 \%$ & 7 & $3 \%$ \\
\hline Disintegration of birth injuries & 13 & $13 \%$ & 2 & $2 \%$ & 15 & $8 \%$ \\
\hline Suture pain & 40 & $40 \%$ & 33 & $33 \%$ & 73 & $37 \%$ \\
\hline $\begin{array}{l}\text { Painful and bleeding } \\
\text { hemorrhoids }\end{array}$ & 19 & $19 \%$ & 13 & $13 \%$ & 32 & $16 \%$ \\
\hline Breast inflammation & 7 & $7 \%$ & 10 & $10 \%$ & 17 & $9 \%$ \\
\hline $\begin{array}{l}\text { Increased risk of postpartum } \\
\text { depression }\end{array}$ & 26 & $26 \%$ & 22 & $22 \%$ & 48 & $24 \%$ \\
\hline
\end{tabular}


The research found a link between the risk of postpartum depression and problems with neonatal care (Table 2). A statistically significant correlation was found between the risk of postpartum depression and problems with neonatal care $(\mathrm{p}=0.016)$. Respondents at risk of postpartum depression had problems with neonatal care in $42 \%$ of cases, compared with respondents without risk of postpartum depression (24\% of persons with problems with neonatal care).

Table 2 Correlation between the risk of postpartum depression \& problems with care of the newborn

\begin{tabular}{|c|c|c|c|}
\hline \multirow{2}{*}{$\begin{array}{c}\text { Postpartum } \\
\text { depression risk }\end{array}$} & \multicolumn{2}{|c|}{$\begin{array}{l}\text { Problems with } \\
\text { neonatal care }\end{array}$} & \multirow[t]{2}{*}{ Total } \\
\hline & Yes & No & \\
\hline Yes & $\begin{array}{c}20 \\
(42 \%)\end{array}$ & $\begin{array}{c}28 \\
(58 \%)\end{array}$ & $\begin{array}{c}48 \\
(100 \%)\end{array}$ \\
\hline No & $\begin{array}{c}36 \\
(24 \%)\end{array}$ & $\begin{array}{c}116 \\
(76 \%)\end{array}$ & $\begin{array}{c}152 \\
(100 \%)\end{array}$ \\
\hline Total & $\begin{array}{c}56 \\
(28 \%)\end{array}$ & $\begin{array}{c}144 \\
(72 \%)\end{array}$ & $\begin{array}{c}200 \\
(100 \%)\end{array}$ \\
\hline \multicolumn{4}{|c|}{ Chi-square test, $p=\mathbf{0 . 0 1 6}$} \\
\hline
\end{tabular}

Depending on the results of the previous hypothesis, we were also interested in whether women cared for by a midwife in the puerperium period had fewer problems with neonatal care (Table 3). There was a statistically significant difference in the incidence of problems with neonatal care according to the presence of a midwife $(p=0.005)$. In women cared for by a midwife in the puerperium period, problems with neonatal care occurred in only $19 \%$ of cases. In women without the care provided by a midwife, problems with the care of the newborn occurred in $37 \%$ of cases.
Table 3 Occurrence of problems in the care of newborns according to the presence of a midwife

\begin{tabular}{|c|c|c|c|}
\hline \multirow{2}{*}{ Midwife care } & \multicolumn{2}{|c|}{$\begin{array}{c}\text { Problems with } \\
\text { neonatal care }\end{array}$} & Total \\
\cline { 2 - 4 } & Yes & No & \\
\hline \multirow{2}{*}{ Yes } & $\begin{array}{c}19 \\
(19 \%)\end{array}$ & $\begin{array}{c}81 \\
(81 \%)\end{array}$ & $\begin{array}{c}48 \\
(100 \%)\end{array}$ \\
\hline No & $\begin{array}{c}37 \\
(37 \%)\end{array}$ & $\begin{array}{c}63 \\
(63 \%)\end{array}$ & $\begin{array}{c}152 \\
(100 \%)\end{array}$ \\
\hline \multirow{2}{*}{ Total } & $\begin{array}{c}56 \\
(28 \%)\end{array}$ & $\begin{array}{c}144 \\
(72 \%)\end{array}$ & $\begin{array}{c}200 \\
(100 \%)\end{array}$ \\
\hline \multicolumn{2}{|c|}{ Chi-square test, $\mathrm{p}=\mathbf{0 . 0 0 5}$} \\
\hline
\end{tabular}

A statistically significant correlation was also found between influencing factors of postpartum depression and midwifery care in the area of breastfeeding $(\mathrm{p}=0.049)$ (Table 4$)$. Respondents who were at risk of postpartum depression and were visited by a midwife in the puerperium period had breastfeeding problems in $31 \%$ of cases, compared with women who did not have midwife care where breastfeeding problems occurred in $59 \%$ of cases.

Table 4 Correlation between influencing factors of postpartum depression \& midwifery care in the area of breastfeeding

\begin{tabular}{|c|c|c|c|}
\hline \multirow[t]{2}{*}{ Midwifery care } & \multicolumn{2}{|c|}{$\begin{array}{c}\text { Breastfeeding } \\
\text { problems }\end{array}$} & \multirow[t]{2}{*}{ Total } \\
\hline & Yes & No & \\
\hline Yes & $\begin{array}{c}8 \\
(31 \%)\end{array}$ & $\begin{array}{c}18 \\
(69 \%)\end{array}$ & $\begin{array}{c}26 \\
(100 \%)\end{array}$ \\
\hline No & $\begin{array}{c}13 \\
(59 \%)\end{array}$ & $\begin{array}{c}9 \\
(41 \%)\end{array}$ & $\begin{array}{c}22 \\
(100 \%)\end{array}$ \\
\hline Total & $\begin{array}{c}21 \\
(44 \%)\end{array}$ & $\begin{array}{c}27 \\
(56 \%)\end{array}$ & $\begin{array}{c}48 \\
(100 \%)\end{array}$ \\
\hline \multicolumn{4}{|c|}{ Chi-square test, $p=\mathbf{0 . 0 4 9}$} \\
\hline
\end{tabular}

We also compared the results of the EPDS scale in the experimental and control groups of women $(n=200)$. We wanted to find out whether the care of a midwife has an effect on more frequent detection of postpartum depressive symptoms (Table 5). The risk of postpartum depres- 
sion occurred in $26 \%$ of women in the experimental group and in $22 \%$ of women in the control group (Table 1). The distribution of the results of the EPDS scale did not differ statistically significantly ( $p=0.775)$ depending on the care or without the care of a midwife. In both groups, the category with a low risk of postpartum depression was the most represented $(74 \% \& 78 \%$, respectively), the category with a high risk of postpartum depression was the least represented $(8 \%$ \& $6 \%$, respectively) (Table 5).

Table 5 Correlation between the risk of postpartum depression \& care of a midwife women with minimal interventions; support for women's natural abilities. Midwives who offer continuity of care often work in groups. The results of the research (9), which included 16,242 women, show that, compared with groups of women who were not cared for by a midwife, these women have lower rates of complications, and that the midwifery care has a positive effect on the mother-child relationship. This is confirmed by the fact that if a woman in the puerperium period does not profit from the care of a midwife, she may be more likely to have health complications, mother-neonatal interaction disorders or postpartum depression.

Women receive information about neonatal

\begin{tabular}{|c|c|c|c|c|}
\hline \multirow{2}{*}{$\begin{array}{c}\text { Midwifery } \\
\text { care }\end{array}$} & $\begin{array}{c}|l| \\
\text { EPDS results } \\
\text { postpartum } \\
\text { depression }\end{array}$ & $\begin{array}{c}\text { Medium risk of } \\
\text { postpartum } \\
\text { depression }\end{array}$ & $\begin{array}{c}\text { High risk of } \\
\text { postpartum } \\
\text { depression }\end{array}$ & Total \\
\hline Yes & $74(74 \%)$ & $18(18 \%)$ & $8(8 \%)$ & $100(100 \%)$ \\
\hline No & $78(78 \%)$ & $16(16 \%)$ & $6(6 \%)$ & $100(100 \%)$ \\
\hline Total & $152(76 \%)$ & $34(17 \%)$ & $14(7 \%)$ & $200(100 \%)$ \\
\hline Chi-square test, $\mathrm{p}=\mathbf{0 . 7 7 5}$ &
\end{tabular}

\section{Discussion}

The World Health Organization estimates that depression is the second leading cause of premature death and disability worldwide. Suffering from depression is still often underestimated. For every 1,000 live births, 100 to 150 women suffer from depression and one or two women suffer from postpartum psychosis (3). In recent years, there have been wide variations in postpartum depression ranging from 0 to $60 \%$. In part, this is due to measurements to determine depression, as self-assessment scales are used; however, social and multicultural factors are likely to affect postpartum depression (7). Postpartum depression occurs in $10-15 \%$, but some authors are of the opinion that the prevalence of postpartum depression of $10-15 \%$ is not representative (4).

In many parts of the world, midwives are the main providers of care for women during pregnancy, childbirth and puerperium period. Elsewhere, these are obstetricians, gynecologists or family doctors. The philosophy of midwifery should be: continuity; trustworthiness; care for care in the hospital, from a pediatrician or from their midwife. In practice, we often encounter inconsistent information, which can subsequently lead to problems with the care of the newborn. These problems can cause a woman's stress, which is one of the possible factors that can affect the development of postpartum depression. Problems with neonatal care occurred in 56 respondents $(n=200)$. In women at risk of postpartum depression, these problems occurred in $42 \%$ of cases, compared with women without any risk of postpartum depression (24\%). According to the obtained results, a statistically significant correlation was found between the risk of postpartum depression and problems with neonatal care $(\mathrm{p}=$ 0.016) (Table 2). Postpartum depression can impair a mother's ability to provide the necessary care for her baby. Children are very sensitive to the quality of care. Often, the mother-newborn interaction may be impaired.

In women with midwifery care, problems with neonatal care occurred in $19 \%$ of cases, and in women without midwifery care, in $37 \%$ of 
cases. There was a statistically significant difference in the incidence of problems with neonatal care according to the presence of a midwife ( $\mathrm{p}=$ 0.005 ) (Table 3). This hypothesis confirmed that the care of a midwife has a preventive effect and is important. As already mentioned, the community care provided by a midwife in the Czech Republic is still considered as above-standard, for which in most cases women have to pay extra money. However, women often have no information about the services and the job description of midwives. Around the world, however, midwifery care is a standard service. In the United Kingdom, for example, women, in most cases, choose the care of a midwife (10). Similarly, in North America, almost $99 \%$ of women would choose midwifery care (11).

Every woman should know that breastfeeding is the ideal nutrition for their baby. There is a presumption (12) that breastfeeding could protect against postpartum depression. Breastfeeding has been shown to reduce cortisol in stressful situations. However, it has not been shown to reduce the risk of postpartum depression or that early termination of breastfeeding increases the risk of postpartum depression. In some cases, the pressure to breastfeed can be a significant stressor (12). However, our research suggests that there is a correlation between postpartum depression and breastfeeding problems $(\mathrm{p}=0.049)$. In respondents who were at risk of postpartum depression and were attended by a midwife in the puerperium period, breastfeeding problems occurred in $31 \%$ of cases, compared to women who did not have midwifery care where breastfeeding problems occurred in 59\% of cases (Table 4).

The distribution of the results of the EPDS scale did not differ statistically significantly $(\mathrm{p}=$ 0.775 ) depending on the care of a midwife. In both groups, the category with a low risk of postpartum depression was the most represented (74\% and $78 \%$, respectively); the category with a high risk of postpartum depression was the least represented (8\% and 6\%, respectively) (Table 5). The risk of postpartum depression occurred in $26 \%$ of women in the experimental group and in $22 \%$ of women in the control group (Table 1). Although the hypothesis was not confirmed and the incidence of postpartum depression is the same in both groups, we believe that early detection and care for women at risk of postpartum de- pression can lead to alleviation or prevention of postpartum depression. This finding is also confirmed by research which shows that a midwife contributes to the prevention of postpartum depression through her care (13) and that her care also leads to improved mental health. Women who have received detailed information and individual care are less likely to have anxiety and depression than women without the necessary care and education (15). Support, understanding and counselling provided by midwives to women after childbirth leads to ensuring their mental well-being. Also, according to Skocir, Hundley (16), a midwife is the most suitable person to detect postpartum depression.

Postpartum depression is still underdiagnosed. Half of the midwives interviewed stated that they used a screening tool in their practice. Almost $60 \%$ of midwives also reported that the incidence of postpartum depression in their practice was lower than the incidence in the general population of $10-15 \%$ (17). Our research revealed the risk of postpartum depression in $24 \%$ of women, $26 \%$ in the experimental group of women and in $22 \%$ in the control group of women (Table 1). As the screening procedure for the detection of postpartum depression is irregular, the occurrence of postpartum depression in midwifery practice is also underestimated.

Although postpartum depression is a global issue, there are regional differences in prevalence and symptomatology. The prevalence of postpartum depression is influenced by countless local and environmental factors, cultural and ethnic elements, religion, healthcare or infrastructure. The EPDS is still the most widely used screening tool. Due to the high prevalence of postpartum depression, early diagnosis is important so as to enable the implementation of preventive measures in order to prevent the disease from progressing to a more serious form. Strategies that help develop the mother-child relationship are also important. Midwifery care for a woman in her puerperium period can be a potential benefit in postpartum depression screening (4).

It is clear from the survey that the care of a midwife leads to the prevention of health complications. Due to her care, a midwife does not identify symptoms of postpartum depression more often, but symptoms of postpartum depression are identified earlier, which she can then ad- 
dress in time. Marks et al. (18) examined the effectiveness of community care in preventing postpartum depression. It turned out that the community care provided by a midwife does not have a decisive influence on psychiatric issues, but it was very successful in involving women in treatment. Therefore, community care is a significant benefit in caring for a mother with mental health problems. Dennis (6) confirms this statement and claims that intensive and professional postpartum care that a midwife can offer according to her competencies is the most promising intervention in the prevention of postpartum depression. In England, for example, there is a program used by midwives to help women after childbirth. The first part of the program is screening using the EPDS scale; the second part takes place at home. Although this is an established practice in England, for example in the USA, the second part of the English system is not used due to a different healthcare system (19). However, screening for postpartum depression by midwives in the United States is supported because it has been shown to be effective within primary care (20).

One of the world's largest organizations for postpartum depression is Postpartum Support International PSI, which has branches around the world. PSI was founded in 1987 in Santa Barbara, California, to bring together self-help groups in various countries. In addition, the association is also a member of a section which promotes interdisciplinary cooperation between various professional groups in the area of delivery of mentally ill women (21). There are not a large number of associations or societies in the Czech Republic that would be interested only in postpartum depression. Women who suffer from this disease can benefit from the help of organizations such as Smile Mom or Deprese.com - don't let the joy go. There is also a portal www.help24.cz, which deals with the issue of human psychology and also provides free psychological counselling. The Psycho-Helpline also works .

The adoption of postpartum depression screening is necessary. The preparation and implementation of screening programs also requires the completion of many other steps, including staff training, the design of an appropriate screening tool, and the formulation and implementation of postpartum screening protocols (19).

\section{Conclusion}

During the puerperium period, a woman requires special care. The woman's body returns to its original state before pregnancy and childbirth. The woman's psyche is also exposed to great strain. The results showed that the care provided by a midwife leads to the prevention of health complications in women in the puerperium period. The care of a midwife does not help identify postpartum depression more often, but symptoms are recognized earlier, and treatment is started. A midwife can also use her care to reduce the predisposition to postpartum depression. The women who were attended by a midwife showed fewer problems with breastfeeding or neonatal care, which are among the predictors of the risk of postpartum depression. Therefore, it is important to inform general public as well as the professional public about the services of a midwife and to get community care in the Czech Republic back to the forefront, thus eliminating the risk factors for postpartum depression.

We recommend: enabling midwives to work independently within their profession with the support of gynecologists and insurance companies; establishing family centers where midwives would provide postpartum community care and lactation counselling; providing comprehensive screening for postpartum depression using EPDS in community care or in gynecological clinics; providing training for midwives on postpartum depression and the screening methods, and supporting the establishment of self-help groups or counselling centers focused on postpartum depression.

\section{References}

1. LASSI ZS, HAIDER BA, BHUTTA ZA (2010) Community-based intervention packages for reducing maternal and neonatal morbidity and mortality and improving neonatal outcomes. Cochrane Database Syst Rev. 2010 Nov 10;(11):CD007754. doi: 10.1002/14651858.CD007754.pub2. Update in: Cochrane Database Syst Rev. 2015;3:CD007754. PMID: 21069697.

2. RATISLAVOVA K (2008) Applies psychology of obstetrics. Praha: Advertising studio AREA s.r.o., 2008, 106 pp.

3. WORLD HEALTH ORGANIZATION. MENTAL HEALTH ACTION PLAN 2013 2020. At: http://apps.who.int/iris/bit- 
stream/10665/89966/1/9789241506021_eng. pdf?ua=1. ISBN 9789241506021 .

4. ZUBARAN C et al. (2010) Screening tools for postpartum depression: validity and cultural dimensions. In African Journal of Psychiatry. 2010, Volume13, No. 5]. At: http:/ /www.ajol.info/index.php/ajpsy/article/viewFile/63101/50970.pdf. ISSN 1994-8220.

5. HAHN-HOLBROOK J, CORNWELL-HINRICHS T, ANAYA I (2018) Economic and Health Predictors of National Postpartum Depression Prevalence: A Systematic Review, Meta-analysis, and Meta-Regression of 291 Studies from 56 Countries Front. Psychiatry, 8, 2018, 10.3389/fpsyt.2017.00248.

6. DENNIS C (2005) Psychosocial and psychological interventions for prevention of postnatal depression: systematic review. In $B M J$. 2005, Volume331, No. 2. At: http://www. bmj.com/content/331/7507/15.full.pdf+html.

7. HIRST, K. MOUTIER, CH. Postpartum major depression. In gynecology after graduation. 2011, vol. 11, no. 1, pp. 30-36.

8. MARTIN C et al. (2012) Perinatal Mental Health: A Clinical Guide. Scotland: University of the West of Scotland, 2012, 536 pp.

9. SANDALL J et al. (2013) Midwife-led continuity models versus other models of care for childbearing women. In The Cochrane $\mathrm{Li}$ brary. 2013, Issue 8. At: http://cfpcwp.com/ MCDG/wpcontent/uploads/2013/02/CD0046 67_standard.pdf

10. FRASER D (1999) Women's perceptions of midwifery care: a longitudinal study to shape curriculum development. June 1999, vol. 26, 99-107 p. At: http://onlinelibrary.wiley.com/ doi/10.1046/j.1523- 536x.1999.00099.x/abstract.

11. EVIDENCE BOOST (2006) Allow midwives to participate as full members of the healthcare team, 2006. At: http://www.alberta-midwives.com/EvidenceBoost_June_E.pdf.

12. MILLER L, LARUSSO E (2005) Preventing postpartum depression. In Psychiatric Clinics of North America. 2005, Volume 34, No. . At: http://www.researchgate.net/publication/498 48106_Preventing_postpartum_depression.

13. HASSANZAHRAEE R et al. (2003) Midwives' Supportive Role in Prevention of Postpartum Depression. In Iranian Journal of Nursing and Midwifery Research. 2003, 7(1).
At: http://ijnmr.mui.ac.ir/index.php/ijnmr/article/view/201.

14. MAC ARTHUR C et al. (2003) Redesigning postnatal care: a randomised controlled trial of protocol-based midwifery-led care focused on individual women's physical and psychological health needs. In Pubmed. 2003, Volume 37, No. At: http://www.ncbi.nlm.nih. gov/pubmed/14622490.

15. LAVENDER T, WALKINSHAW S (1998) Can Midwives Reduce Postpartum Psychological Morbidity? A Randomized Trial. In Blackwell Science. 1998. At: http://onlinelibrary.wiley.com/doi/10.1046/j.1523536X.1998.00215.x/pdf.

16. SKOCIR AP, HUNDLEY V (2006) Are Slovenian midwives and nurses ready to take on a greater role in caring for women with postnatal depression? In Midwifery. 2006, Volume 22, No. 1. At: http://www.popline. org/node/169689.

17. ZANDER S (2006) Certified Nurse-Midwives' Beliefs About and Screening Practices for Postpartum Depression: A Descriptive Study. In School of Nursing Scholarly Works. 2006. At:http://digitalcommons.uconn.edu/ son_articles/39/

18. MARKS MN, SIDDLE K, WARWICK C (2003) Can we prevent postnatal depression? A randomized controlled trial to assess the effect of continuity of midwifery care on rates of postnatal depression in high-risk women. In J Matern Fetal Neonatal Med.2003,Volume13, No. . At: http://www.ncbi.nlm.nih. gov/pubmed/12735413.

19. TAHIRI S, SOPJANI I, EJUPI V, BEQIRI L, BERISHA A (2020) Postpartum Depression and the Role of Midwives in Its Early Detection. Open Journal of Nursing, 2020. 10(8), 745-757.

20. BEEBER L The Pinks and Blues: Symptoms of Chronic Depression in Mothers during Their Children's First Year. American Journal of Nursing, 20002. 102, 91-98. At. https://doi.org/10.1097/00000446200211000-00033.

21. POSTPARTUM SUPPORT INTERNATIONAL. [online]. (C)2010 - 2014. [cit. 20216-10]. At: http://www.postpartum.net/. 